\title{
Hearing-impaired patients the medical setting
}

\author{
JOHN E. MEYERS, MEd \\ JULIAN J. MELHADO, DO, PhD \\ DANIEL R. FRANCES, DO
}

\begin{abstract}
Physicians may encounter unique problems in providing medical services to patients with severe hearing impairments, and they may not be aware of the legal rights of these patients to specific services under section 504 of the Rehabilitation Act of 1973. Most physicians have relatively little contact with the hearing impaired and thus are unprepared for the unique challenges presented by this population. The authors present basic information needed by physicians and their staffs to appropriately serve the hearing impaired.
\end{abstract}

Census statistics show that approximately $4.3 \%$ of the population of the United States has a severe to profound bilateral hearing loss. ${ }^{1}$ Statistically, then, any given medical practice would include some hearing-impaired patients. Since most physicians have no regular contact with this population, providing medical services to the hearing impaired may prove to be quite challenging at times. Significant personality, cultural, developmental, and language differences exist between the hearing impaired and the non-hearing impaired. ${ }^{2-5}$ In this article, the focus will be on the language and communication of the hearing impaired as these directly affect the services they receive from the medical community.

\section{Communication}

Physicians, like many laypersons, may have misconceptions about the way hearing-impaired people communicate. Some of the hearing impaired use lipreading or speech reading to interpret the oral expressions of others, or hearing aids (or both). Others use sign language to express themselves.
Most of the hearing impaired use a combination of methods including speech and writing.

Speech reading is a learned skill by which the hearing-impaired person gleans meanings from facial cues and lip movements. ${ }^{6}$ Speech reading is difficult, since only about a third of the speech sounds in English are produced with visible movements of the lips. ${ }^{7}$ Of these, the average adult with a severe prelingual hearing impairment can speech read about $25 \%$; the average child, about $5 \% .8$ Speech reading alone is not very effective.

The attempts of the hearing-impaired person to communicate with a hearing person through the medium of speech may be likewise ineffective. In many cases, the "deaf voice" leads to misunderstanding. For example, one physician thought a hearingimpaired patient who was trying to describe a dream was having hallucinations.

Relying on written communication can also lead to misinformation. In the United States, the average person with a severe hearing impairment reads English at or below the fifth-grade level. Only $12 \%$ of those with a profound hearing impairment show competency in the English language. Only $4 \%$ are proficient in speech reading or speaking. ${ }^{9}$ When many hearing-impaired persons write in English, their syntax and sentence structure often are unusual. This difference is due not to poor English training but to the interference of a primary, unwritten sign language called Ameslan, or ASL. ${ }^{10}$

The structure of ASL, the language of the deaf that is understood by nearly all hearing-impaired persons, is not related to the structure of English. ${ }^{11}$ When writing, many hearing-impaired persons use English words in an ASL sentence structure. This can be confusing for both the writer and the reader. The hearing-impaired person is writing in a language in which he or she has limited skills, and the reader is attempting to decipher the meaning 
of sentences written in a foreign syntax (ASL) using English words. In English, the sentence structure is subject, verb, object. In ASL, the order is time indicator (past, present, future), object, verb, subject, and other modifiers. ${ }^{12}$ For example, in English, we say "I am going to the store. It's quite far." In ASL, it would be "Now [present] store go I[!] far." As one can see, translation from ASL to English, particularly in a written form, is difficult.

\section{Rights of hearing impaired: The Rehabilitation Act}

In April 1977, the provisions of section 504 of the Rehabilitation Act of $1973^{13,14}$ were extended to all recipients of federal funds, including hospitals and, in some instances, individual physicians. ${ }^{15}$ As a result, all medical institutions with 15 or more employees are required to provide interpreters and auxiliary aids for their hearing-impaired patients at no cost to the patient. When receiving medical services, many hearing-impaired patients require interpreters. In this respect, the rights of the hearing impaired are often viewed as being intrusive into the business workings of hospitals and clinics; therefore, equal access is often denied because it is bothersome, costly, or not necessary. However, the courts have taken another view.

In the case of Snow $v$ New York, ${ }^{16} 98$ AD 2d 442, a profoundly deaf patient had been misdiagnosed and treated by a variety of medical personnel. The ruling of the court made $\mathrm{Mr}$ Snow $\$ 1.5$ million richer and the medical personnel $\$ 1.5$ million wiser.

\section{What to do}

The use of interpreters and adaptive equipment is mandatory by law. (The two most common pieces of adaptive equipment other than hearing aids are telephone communication devices for the deaf [TDD] and TV closed-caption decoders.) These services must be provided if they are requested by a hearing-impaired patient; they also may be waived by the patient. Interpreters can be contacted through a central agency or through an interpreter referral service. If a referral service is not available, a list of interpreters should be maintained at the institution, usually at the admissions desk. It is most convenient to arrange for the interpreter at the time the medical appointment is made. It is best to use only certified interpreters, who have met competency standards and whose rigorous code of ethics requires that they accurately interpret (to the best of their ability) what is said. Well-mean- ing family members may not be able to interpret objectively.

It is common practice to give the interpreter a few minutes to become familiar with the communication style of the hearing-impaired patient. After this short familiarization, the interview can begin. The best arrangement is for the interviewer to face the hearing-impaired person and speak in the first person. The interpreter should be off to one side of and slightly behind the interviewer. The interpreter will then voice the signs of the patient and sign the words of the interviewer. In this way, the rapport is established between the patient and the physician and not between the patient and the interpreter.

When interviewing the patient, it is best to keep in mind that the hearing-impaired person is the final judge of the communication compatibility of the interpreter. If the communication styles of the interpreter and the hearing-impaired person are incompatible, a different interpreter should be summoned.

Another consideration is the cultural factors that affect communication. Many statements in English do not translate well into ASL. For example, a common question might be, "What brought you here today?" A common response might be, "The bus." This type of response is quite normal in an ASL context and does not indicate the patient's inability to abstract. A more appropriate way to phrase the question might be, "Why did you come to the doctor today?" This type of question is direct and translates more clearly. If unusual responses are obtained during the interview, the interviewer should rephrase the questions instead of just repeating them.

In the case of an emergency, communication with the patient should be made in the manner suggested here until the interpreter arrives. These same suggestions also will apply if the patient waives the interpreter services:

- Provide adequate lighting so that the hearingimpaired person can clearly see the speaker's face.

- Look directly at the patient, enunciating words normally, but at a slightly slower pace. Exaggerating words will distort the lip movements and make speech reading more difficult.

- Rephrase rather than repeat if the person does not understand the question.

- Avoid or reduce background noise as much as possible.

- Ask the patient what you might do to make con- 
versation easier. Nodding the head may not indicate understanding.

- Consider using writing, pictures, mime, gestures, and other methods that might help communication in this situation.

- Consider consultation with specialists who work with the hearing impaired. Significant cultural differences come into play, particularly in mental health settings. Specialists usually can be identified by a TDD or TTY indication by the number in the phone book. Some state agencies that provide service to or coordinate services for the hearing impaired may also be able to provide referral information. Information can be obtained from national information centers for the hearing impaired, such as the American Speech, Language, and Hearing Association (1-800-638-8255) and Gallaudet University (202-651-5000). Other organizations for the deaf may also be of assistance.

\section{Summary}

In many instances, medical personnel attempt to provide services to hearing-impaired patients without establishing adequate communication. In such instances, it is incorrect to assume that the hearingimpaired patient is receiving a "full measure" of service for the money paid or that "equal access" to services has been provided. The use of interpreters, specialists, and other types of assistance (including adaptive equipment) is necessary and proper. Physicians, both generalists and specialists, are encouraged to follow these recommendations so as to make full medical treatment accessible to patients with hearing impairments.

1. United States Bureau of the Census: Current Population Report, Household Economic Studies, Series P-70, 8, Table 2.

2. Talkington L, Reed K: Rorschach response patterns of hearing impaired retardates. Percep Mot Skills 1969;29:546.

3. Bolton B: Personality studies of deaf adults. Rehabilitation Research and Practice Review. 1972;3(4):11-17.

4. Wilson J, Rapin I, Wilson B, et al: Neuropsychological function of children of severe hearing impairment. J Speech Hear Res 1975;18:634652.

5. Kelly R, Tomlinson-Keosy C: Hemispheric laterality of deaf children for processing words and pictures visually presented to the hemisfields. Am Ann Deaf 1977;122:525-533.

6. Cox DP, Lloyd L: Audiologic consideration, in Lloyd L (ed): Communication, Assessment, and Intervention Strategies. Baltimore, University Park Press, 1976; pp 123-193.

7. Hardy MP: Speech reading in Davis H, Silverman RS (eds): Hearing and Deafness. New York, Holt, Rinehart \& Winston, Inc, 1970; pp 33345.

8. Vernon M, Koh S: Early manual communication and deaf children's achievement. Am Ann Deaf 1970;115:527-536.

9. Schlesinger HE, Meadow KP: Deafness and Mental Health: A Developmental Approach. San Francisco, Langley Porter Neuropsychiatric In- stitute, Project \#14-P-55270/9-03 (RD 2835-S). US Department of Health, Education and Welfare, 1971.

10. Klima E, Bellugi U: The signs of language in child and chimpanzee, in Alloway T (ed): Communication and Effect. New York, Academic Press, Inc, 1972, pp 67-96.

11. Klima E, Bellugi U: The Signs of Language. Cambridge, Mass, Harvard University Press, 1979, p 4.

12. Haas $\mathrm{E}$, Sams K: A method for erasing gestural language structure Percept Mot Skills 1987;64:391-397.

13. Public Law 93-112, 93d Congress, HR 8070, Sept 26, 1973.

14. Public Law 93-516, 93d Congress, HR 17503, Dec 7, 1974.

15. Section 504 of the Rehabilitation Act 1973 Fact Sheet, Handicapped Person's Civil Rights Under Federal Law, Department of Education, Office of Civil Rights, Washington, DC, October 1980.

16. Snow $v$ State of New York, 98 AD 2d 442, cited as 469 NYS 2d 959 (AD 2 Dept 1983).

From the department of psychiatry and behavioral science, University of Osteopathic Medicine and Health Sciences College of Osteopathic Medicine and Surgery, Des Moines.

Reprint requests to Mr Meyers, 2573 NE Laura St, Hillsboro, OR 97124 